
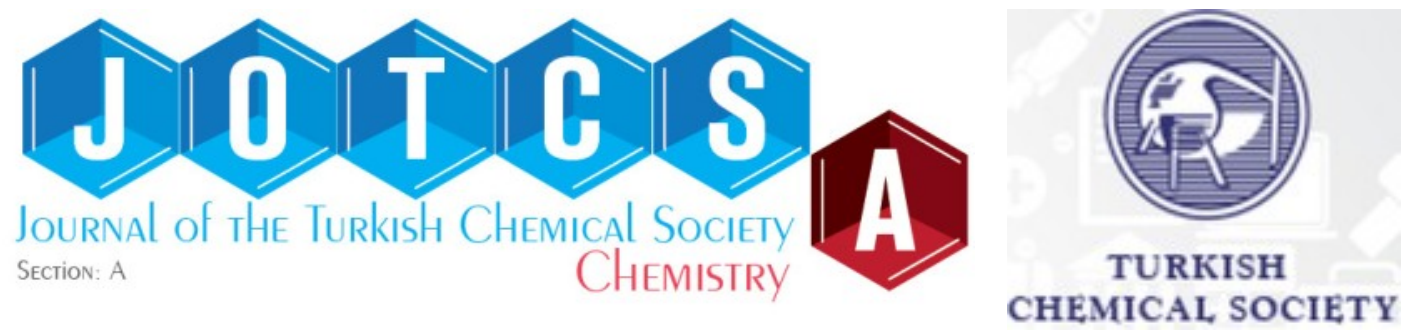

\title{
A Survey on Various Methods of Extraction and Recovery of Thorium
}

\author{
Sugyani Dash¹ ${ }^{1}$, Pallabi K. Hial' ${ }^{\text {(D) }}$, Sagarkanya Senapati ${ }^{1}$ (D), and \\ Biswajit Dalai $2 *$ (D) \\ ${ }^{1}$ PG Scholar, Department of Physics, School of Sciences, GIET University, Gunupur, Odisha 765022, India \\ ${ }^{2}$ Department of Physics, School of Sciences, GIET University, Gunupur, Odisha 765022, India
}

\begin{abstract}
In this survey, some methods of extraction of thorium such as selective extraction of thorium using phosphorodiamidate, selective cloud point extraction of thorium, extraction of thorium from sulfuric acid baking and leaching of monazite, extraction of thorium from chloride solution using Schiff base were discussed. The decomposition of monazite was manifested by sulfuric acid baking and leaching at an elated temperature. The recovery of thorium (Th) from various sources of rare earth and some selective extraction of thorium by using phosphorodiamidate as an extractant was also reported. Using a special synthesized surface-active ionic liquid extractant (SAIL), the cloud point extraction of thorium was analyzed. A synthesized Schiff base was applied for the extraction of thorium in the strategic solvent extraction method. Thorium, using a-amino phosphate extractant from bastnaesite, recovery by using Cyanex 572 and N1923, recovery of Th from industrial residues and recovery of Th from radioactive waste by using IREPO and monazite leached solution were discussed. In this study, the recovery of thorium from the industrial residue as well as from radioactive residue was also discussed.
\end{abstract}

Keywords: Extraction, Thorium, Monazite, SAIL, Cyanex ${ }^{\circledR} 572$

Submitted: June 23, 2021. Accepted: October 27, 2021.

Cite this: Sugyani D, Pallabi KH, Sagarkanya S, Biswajit D. A Survey on Various Methods of Extraction and Recovery of Thorium. JOTCSA. 2021;8(4):1197-210.

DOI: https://doi.org/10.18596/jotcsa.955211.

*Corresponding author. Email: biswajit@giet.edu.

\section{INTRODUCTION}

The history of human development is often told by the various form of energy. At first, it was muscle, and later when humans learned to control fire, it was heat energy. Eventually using coal and oil, the world was industrialized. With a growing population, the consumption of energy has been increased. This growing energy demand is met when a human entered into this atomic era. The energy harvested from the splitting of a nucleus has made humans the most advanced species on earth. When the demand for nuclear energy increased, the demand for nuclear fuel like thorium (Th) and uranium (U) is also increased. Even though thorium is not fissile, it is referred to nuclear energy since it is three to four times more abundant on the surface of the earth than uranium and it also provides the most promising options for nuclear power generation in terms of fuel efficiency and economy (1). Lots of researches had been conducted to find a source of energy that would substitute the place of earth's energy resources that has been depleting rapidly day-by-day. The very promising and environment-friendly approach for meeting the ever-growing energy demand is nuclear energy with the least amount of nuclear waste. One of the greenest energy productions is the thorium reactor $(2,3)$. The possibility of thorium being the nuclear fuel, has given more importance to the production of thorium worldwide and Thorium is a naturally occurring radioactive material $(4,5)$. 


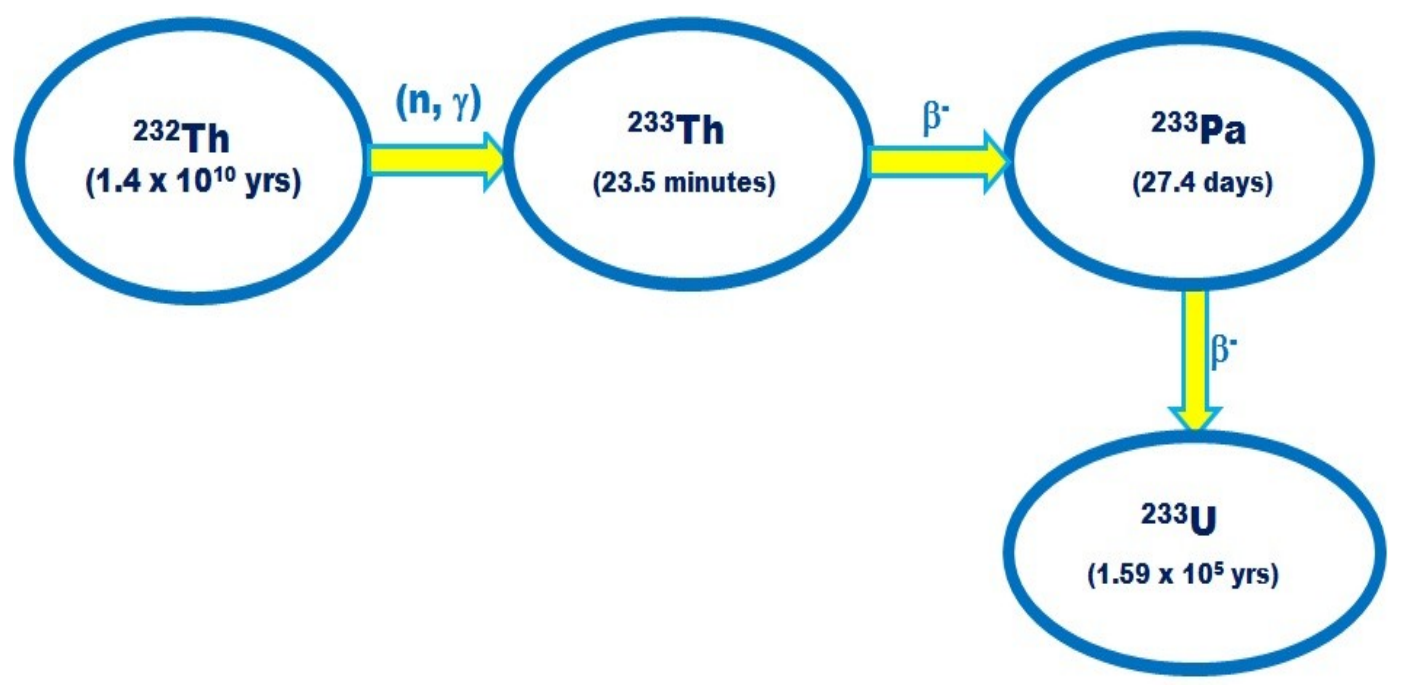

Figure 1: Production of uranium from Thorium (1).

Normally thorium isotopes exist as thorium-232 ( $\left.{ }^{232} \mathrm{Th}\right)$ and its half-cycle is around 14 billion years. ${ }^{232} \mathrm{Th}$ is a fertile material that doesn't undergo fission reaction by itself. But a fissile material, i.e., uranium, is produced from its two-beta decay reaction of thorium with a neutron (Figure 1 ). Out of all nuclear fuels, thorium(IV) oxide $\left(\mathrm{ThO}_{2}\right)$ has more advantages compared to uranium because of its lower thermal expansion than uranium(VI) oxide $\left(\mathrm{UO}_{2}\right)$ and despite having a similar isometric structure, it is relatively inert $(3,4)$. The high thermal conductivity of $\mathrm{ThO}_{2}$ makes it better fuel for nuclear reactors and the thorium fuel is considered an efficient fuel because of its lower hazard nuclear reaction accidents as well as its lower nuclear by-products. In the reactor, there will be no need for fuel reprocessing. The increasing awareness of fuel resources is changing its attitude towards the use of thorium as a fuel resource (5-7). The role of thorium in futuristic green energy production, gives rise to the demand for thorium extraction. There are various methods for production of Thorium like extraction of thorium by using phosphorodiamidate as extractant, selective cloud point extraction of Th, selective extraction of Th by sulfuric acid baking and leaching of monazite, extraction of Th using a Schiff base etc. (8-12). The extraction behaviors of U(VI) and Th(IV) were investigated by Tan et al. (13) using di(1-methyl-heptyl) methyl phosphonate (DMHMP) as an extractant and kerosene as a diluent. Some novel extractants were synthesized for the separation of thorium and rare earth (RE) by Dong et al. (14). Among the synthesized neutral organophosphorus extractants, n-octyl phosphate diphenyl (ODP) revealed excellent extraction efficiencies and selectivities for Th(IV). The extraction mechanisms of uranium and thorium were studied by Nasab (12). Taguchi's method (12) was used to determine the optimum conditions for the separation of uranium and thorium using neutral extractants. In solvent extraction method, this method has been proposed as powerful method of experimental design (12)

$$
(S / N)_{i}=-10\left(\frac{1}{n} \sum_{i}\left(\frac{1}{y_{i}^{2}}\right)\right)
$$

Where the signal to noise $(\mathrm{S} / \mathrm{N})$ ratio is used to determine the best experimental conditions, $y_{i}$ is the experimental value and $n$ is the number of tests in the experiment. In recent years, the extraction and recovery of thorium ions and their separations from various geological rare earth minerals have gained vital significance due to their wide applications in industries. The different extraction processes of thorium in a single review paper were not found in literatures and thus we have attempted to analyze the processes herewith.

\section{METHODS OF EXTRACTION}

\section{Selective Extractions from Rare Earth by Using Phosphorodiamidate as an Extractant}

In this method of extraction, an extractant named phosphorodiamidate was synthesized. To separate thorium from rare earth, the medium for the extraction chosen was nitrate medium. The molecular structure for this extractant is given in Figure 2. 


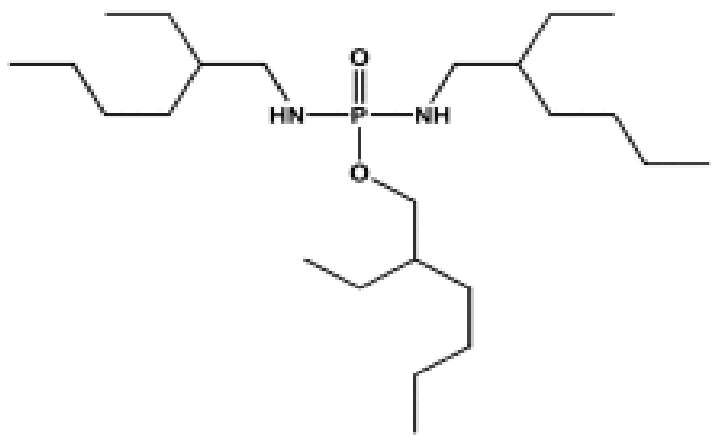

Figure 2: Molecular structure of phosphorodiamidate ligand, designated as $\mathbf{L}(8)$.

The molecular formula for this extractant is 2Ethylhexyl-N, N'-di(2-ethylhexyl) phosphorodiamidate. The above extractant was added with a required concentration in $\mathrm{n}$-heptane. The standard solution with concentrated nitric acid was prepared by dissolving corresponding oxides. The prepared solution was diluted with distilled water. The experiment was carried out in a temperaturecontrolled shaker bath at $298 \mathrm{~K}$. For higher efficiency, nitrate medium with acidity ranging from $0.01 \mathrm{~mol} / \mathrm{L}$ to $7 \mathrm{~mol} / \mathrm{L}$ was taken in the extraction process. The extraction of thorium in a different acidic medium generally decreases by the increase in hydration energy of their ions and decrease in hydrophobicity of the extracted complex. The maximum loading capacity of Th in this method was about $48.56 \mathrm{~g}$ Th per liter of working solution with $0.69 \mathrm{~mol} / \mathrm{L}$ of phosphorodiamidate at a $2.1 \mathrm{~mol} / \mathrm{L}$ concentrated nitrate medium. The extraction of Th(IV) and $U(V I)$ from dilute nitric acid solution by several neutral phosphorus-based extractants has been studied as a function of temperature in the range of $0-50{ }^{\circ} \mathrm{C}$ by Kalina et al. (15). The order of extraction capacity of Th from the different medium: $\mathrm{H}_{2} \mathrm{SO}_{4}<$ $\mathrm{HCl}<\mathrm{HNO}_{3}$ (16-18). (16-18). In case of phosphoric acid, when the concentration is increased from 1 $\mathrm{mol} / \mathrm{L}$ to $6.5 \mathrm{~mol} / \mathrm{L}$, the thorium stripping becomes $40 \%$ to $70 \%$. When the concentration of the extractant (L) is increased, the extraction efficiency of thorium has been found more than REs. To reach higher extraction efficiency, the thorium extraction was studied with the acid concentration ranging from $0.01 \mathrm{~mol} / \mathrm{L}$ to $7 \mathrm{~mol} / \mathrm{L}$ in different acid medium $(8,16)$. The stripping of thorium by nitric acid confirmed that the loaded thorium can not be stripped even at high nitric acid concentration. There are maximum value for the stripping efficiency at about $1.5 \mathrm{~mol} / \mathrm{L}$ for $\mathrm{H}_{2} \mathrm{SO}_{4}$ and $2.4 \mathrm{~mol} / \mathrm{L}$ for $\mathrm{HCl}(8,16)$. $(8,16)$. The higher acid concentration is more helpful for separation of REs. In this method, thorium is extracted in ionic form, Th(IV). The extraction is spontaneous and exothermic.

\section{Cloud Point Extraction (CPE)}

It is an eco-friendly method of extraction $(9,19-$ 26). This method of extraction is considered noble because it is inexpensive, fast, selective, precise, and accurate. The procedure is considered green extraction as this method consumes a minimum amount of toxic organic solvents. Figure 3 shows how the cloud point extraction of metal can be done.

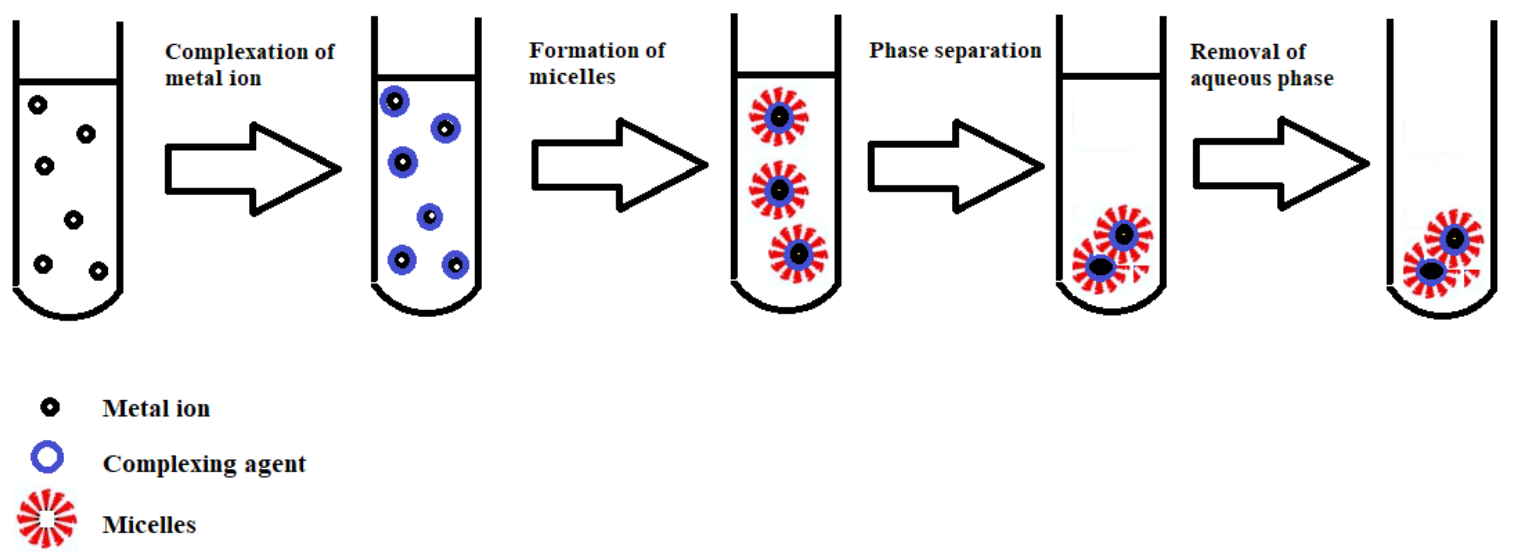

Figure 3: Cloud point extraction method (19).

In the experiment, a known amount of thorium was mixed with an Arsenazo III solution of 0.001 $\mathrm{mol} / \mathrm{L}$ concentration in a $10 \mathrm{~mL}$ centrifuge tube. Then in the Th-Arsenazo III complex, the solutions: $1.0 \mathrm{~mL}$ of Triton $\mathrm{X}-100,0.5 \mathrm{~mL}$ of $\mathrm{KI}$ $(0.01 \mathrm{~mol} / \mathrm{L})$, and $2.5 \mathrm{~mL}$ of newly synthesized tetra-cationic surface-active ionic liquid (SAIL) based on tetraazonia-tricyclodecane derivative $(0.001 \mathrm{~mol} / \mathrm{L})$ were added respectively with an adjusted $\mathrm{pH}$ of 5.0. After taking the solution with deionized water to the mark, it was left in a thermostatic bath $(353.15 \mathrm{~K})$ for $30 \mathrm{~min}$ to an induced separation. Since the surfactant is denser than water, the solution gets separated into two 
phases and the surfactant-rich phase settled through the aqueous phase. Then the tube was cooled down in an ice bath and centrifuged at 6000 $\mathrm{rpm}$ for $10 \mathrm{~min}$. Then the aqueous phase was decanted leaving the surfactant-rich phase at the bottom of the tube. The surfactant-rich phase is then diluted with methanol to decrease the viscosity. After that, the extracted sample is moved to the quartz cell for a spectrophotometric determination as shown in Figure 4.

As per the work of Z F Akl and M. A. Hegazy (26), the highest extraction efficiency was achieved at
$\mathrm{pH} 5.0$ with $2.5 \times 10^{-3} \mathrm{~mol} / \mathrm{L}$ SAIL and $1.0 \%(\mathrm{v} / \mathrm{v})$ Triton $X$ - 100. At the optimized conditions, the developed method exhibited a linear working range from 10 to $100 \mathrm{ng} / \mathrm{mL}$ with a detection limit of $0.77 \mathrm{ng} / \mathrm{mL}$. $0.77 \mathrm{ng} / \mathrm{mL}$. The temperature also plays a vital role. For efficient extraction, the optimum temperature is $80^{\circ} \mathrm{C}$. When the sample is spiked with preconcentrated Th(IV) by a factor 20 , then the extraction percentage of thorium increases more than $98 \%$. This work reported the development of a green, sensitive, selective, and inexpensive method for extraction Th(IV).

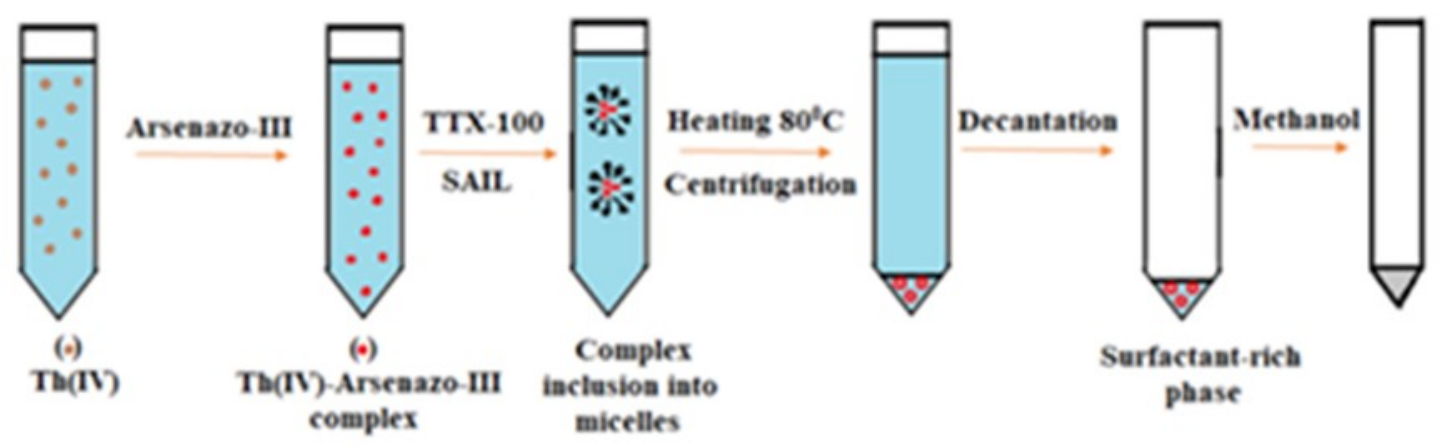

Figure 4: Spectrophotometric determination after cloud point extraction of Th (25).

\section{Selective Extraction of Th by Sulfuric Acid Baking and Leaching of Monazite}

Monazite is one of the major sources of thorium and many rare earth elements (REE). In sulfuric acid baking, the rare earth elements were converted into sulfates and those sulfates get dissolved in water leaching process. Monazite was either processed by sulfuric acid baking or alkaline digestion (10). In this process of extraction, at first monazite-sulfuric acid mixture was digested in the stirred reactor at $200{ }^{\circ} \mathrm{C}$ to $246{ }^{\circ} \mathrm{C}$. Then the baking was carried out at various temperatures between $200^{\circ} \mathrm{C}$ and $800^{\circ} \mathrm{C}$ (27). After the baking, the heated sample was removed from the heated furnace and cooled. The cooled sample was ground to a fine powder before it was leached at $40: 1$ liquid to solid ratio at $20^{\circ} \mathrm{C}$ to $29^{\circ} \mathrm{C}$ in $0.9 \mathrm{M}$ sulfuric acid for two hours. Then the separation of solid and liquid was done by vacuum filtration. The monazite bearing different concentrates have different bake temperatures. Individual rare earth is not easy to separate from each other because of their similar chemical and physical properties. Before the advancement in industrial solvent extraction, ion exchange techniques were prominent. In environmental and high-tech applications, rare earths are non-replaceable and indispensable because of their unique electrochemical, luminescent and magnetic properties. To satisfy the diverse application of rare earth, it is mined, screened, and leached for separating it into proper feed materials (28). (28). In this method, one of the influencing factor is precipitation $\mathrm{pH}$. It is ranging from 2.5 to 5.5 for thorium. But now-adays solvent extraction is accepted as the most appropriate technique for separating rare earth commercially $(29,30)$. In this method of extraction, the behaviors of rare earth play a vital role. The separation of uranium and thorium in pure products can be achieved by this method using sulfuric acid liquor and one of the important variables to be considered in the process is the dosage of acid and dilution (31-33). In sulfuric acid baking of rare earth, uranium and thorium get converted into soluble sulfate (34). In the $\mathrm{HCl}$ leaching system, the issue of acid consumption is more pronounced. For mineral decomposition in industry, sulfuric acid baking is one of the major processes. This process is responsible for $81 \%$ of the world's rare-earth production. There are numerous techniques to investigate the extraction of rare earth metals, but only a few of them are found to be effective and successful. Sulfuric acid baking and leaching are one of them (27, 35-37). The flow chart of sulfuric acid decomposition of monazite is displayed in Figure 5. Various conditions for the baking of minerals, e.g. monazite, have been presented by numerous researchers $(27,35-57)$. This extraction method is exothermic process. The baking of monazite with sulfuric acid gives an enthalpy of $-171 \mathrm{~kJ} / \mathrm{mol}$. J. Demol et al. (27) found that the sulfation reaction of monazite with acid resulting in more than $90 \%$ solubilization of rare earth elements phosphate and thorium. Their result shows the virtual complete dissolution of rare earth, phosphate, and thorium 
during leaching after $250{ }^{\circ} \mathrm{C}$ bake. A thorium phosphate type precipitate was formed during leaching after baking at $300{ }^{\circ} \mathrm{C}$ and it leads to sharp decrease in extraction of phosphate and thorium. This method requires high temperature and excessive acids for digestion which involves a number of risk factors while handling the steps.

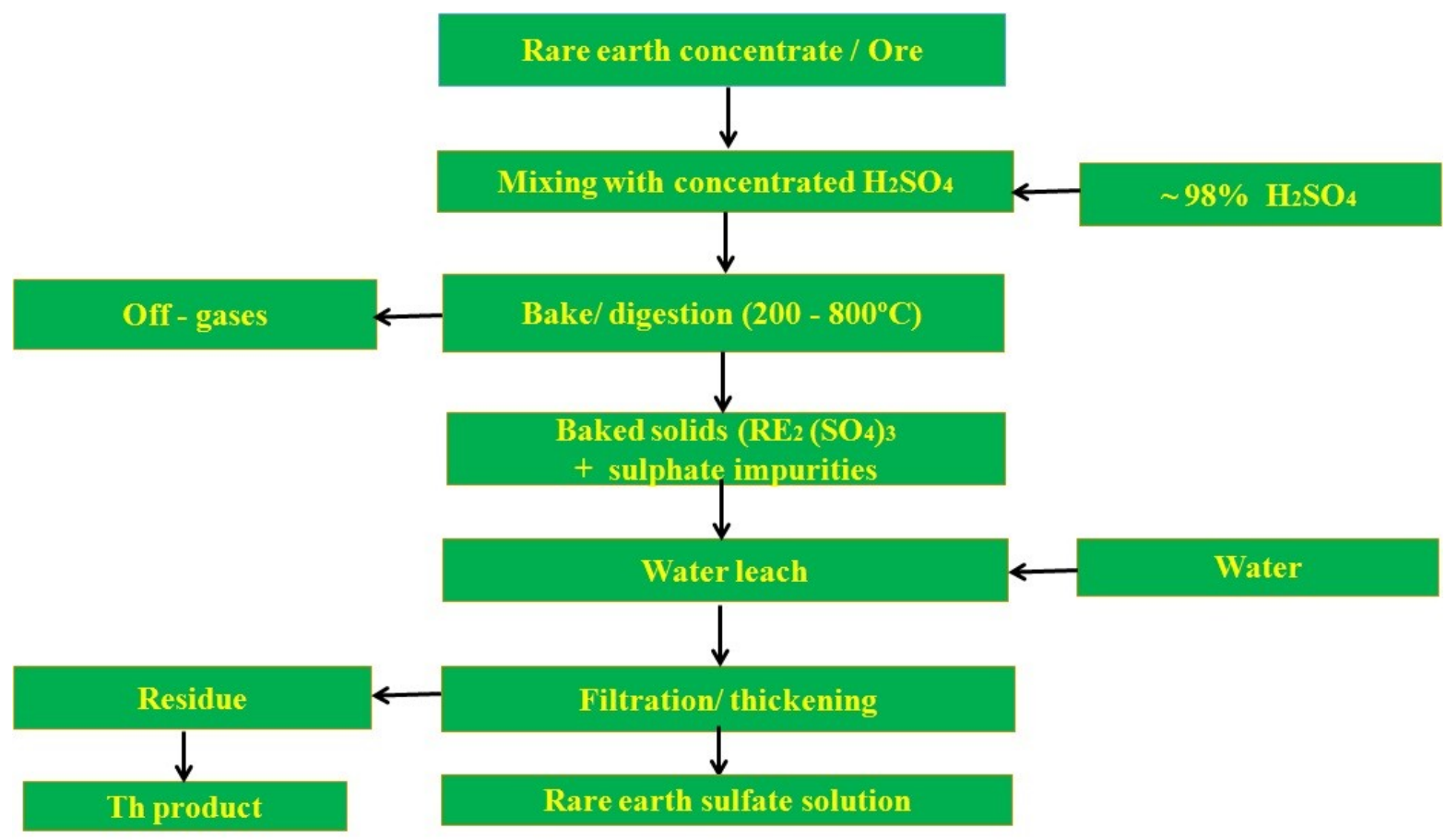

Figure 5: Sulfuric acid treatment of a rare earth mineral concentrate (37).

\section{Extraction of Thorium (IV) from Chloride Solution using Schiff Base}

In this strategic method of solvent extraction for thorium selective group extractants such as neutral phosphate (12), amines $(12,58)$, oximes (59), phosphoric acid $(60,61)$ and, Schiff base $(11,62$, 63) were employed. In this process of extraction, initially, a synthesized Schiff base (AcPh) was applied for the extraction of thorium from standard solution (1000 $\mathrm{mg} / \mathrm{L}$ of Th IV) which was prepared by dissolving $2.535 \mathrm{~g}$ of thorium nitrate in acidified distilled with $10 \mathrm{~mL}$ of concentrated $\mathrm{HCl}$. The preparation of the Schiff base is shown in Figure 6.<smiles>Nc1ccccc1O</smiles><smiles>CC(=O)CC(C)=O</smiles><smiles>CC(=O)C/C(C)=N/c1ccccc1O</smiles>

2-Aminophenol

Figure 6: Preparation of the Schiff base (AcPh) (11).

After adding AcPh, then the sample mixture was dissolved in a mixture of diethyl ether and chloroform at the ratio of 2:3. After that sodium malonate was added to the sample containing Th(IV) in chloride form. A dilute solution of $\mathrm{HCl} / \mathrm{NaOH}$ was added to obtain the desired $\mathrm{pH}$. Then the sample was equilibrated by shaking it for about 7 minutes in a glass with an appropriate volume of the organic phase. After equilibration, Th in ionic form was separated from its aqueous phase $(63,64)$. The $\mathrm{pH}$ value $(\approx 6.5)$ and concentration of Schiff base are influencing factors for extraction. When the concentration of Schiff base is increased from $0.001 \mathrm{M}$ to $0.002 \mathrm{M}$, the extraction efficiency of Th(IV) increases from $44 \%$ to $96.2 \%$ provided the organic phase to aqueous 
phase is to be $1: 3$. M. F. Cheria et al. (11) reported that the maximum extraction efficiency of thorium was obtained at $0.02 \mathrm{M} \mathrm{AcPh} / \mathrm{chloroform}$ and diethyl ether mixture, $3: 1$ aqueous to the organic ratio for $5 \mathrm{~min}$ contact time at room temperature. The extraction process using Schiff base in chloride medium gives an increased sensitivity of analysis of thorium ions in rock samples. Using this method thorium can be extracted about $330 \mathrm{mg} / \mathrm{kg}$ approximately. When phophorodiamidate extractant used for the extraction, the extraction capacity was found to be $48.55 \mathrm{~g}$ per liter of the sample solution. sample solution. The efficiency of stripping decreases gradually with the increase in temperature above room temperature. For efficient extraction the room temperature is considered optimum. This extractant is considered noble as it makes selective extraction of Th from rare earth possible.

\section{RECOVERY OF THORIUM USING DIFFERENT TECHNIQUES, EXTRACTANTS, AND FROM RADIOACTIVE WASTE}

Recovery of Thorium(IV) by a-amino phosphate Extractant in Sulfate Medium and from Leach Solution with Cextrant 230

In this process of recovery, a-aminophosphate extractant and Cextrant 230 were used to recovery Th(IV) in sulfate medium and by using leach solution respectively. Here the use of the amine group in phosphate increases the extraction of Th(IV). Bastnasite leaching can be used, in which purities of Th were increased by $98 \%$. Due to the increasing global demand of energy, the recovery of Th, and $U$ from various sources have drawn great attention at present time $(64,65)$. Bastnasite $\left((\mathrm{RE})\left(\mathrm{CO}_{3}\right) \mathrm{F}\right)$, monazite $\left(\left(\mathrm{RE}\left(\mathrm{PO}_{4}\right)\right.\right.$, xenotime $\left(\mathrm{YPO}_{4}\right)$, and $\mathrm{RE}$-bearing clay have been used as rare earth minerals $(65,66)$. Recently, aminophosphate compounds have drawn the attraction of researchers, and have been extensively used as extractants, herbicides, anticancer agents, etc. It also shows marvelous extractive properties (67-71). Here metals were analyzed using an inductively coupled plasma optical emission spectrometer (72, 73). To determine the $\mathrm{pH}$ of an aqueous solution, $\mathrm{PHS}-3 \mathrm{C}$ digital meter was used. The molecular structure of Cextrant 230 is shown in Figure 7.

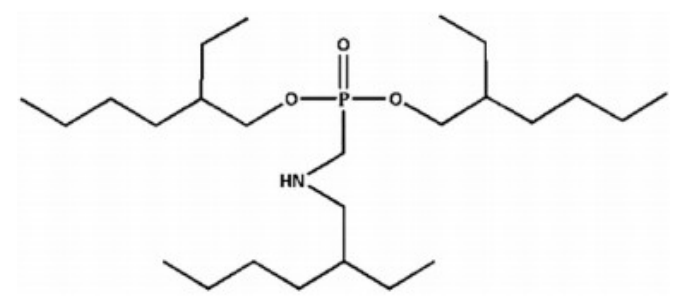

Figure 7: Molecular structure of Cextrant 230 (73).

Cextrant 230 is the most important extractant for the recovery of radioactive elements $T h$ and $U$ from an aqueous solution. It contains aluminium and iron in a sulfate medium. The extraction process of $T h$ and $U$ with cextrant 230 is exothermic (72-74). The flow chart of separating cerium (IV) and thorium (IV) from bastnaesite leaching is shown in Figure 8.

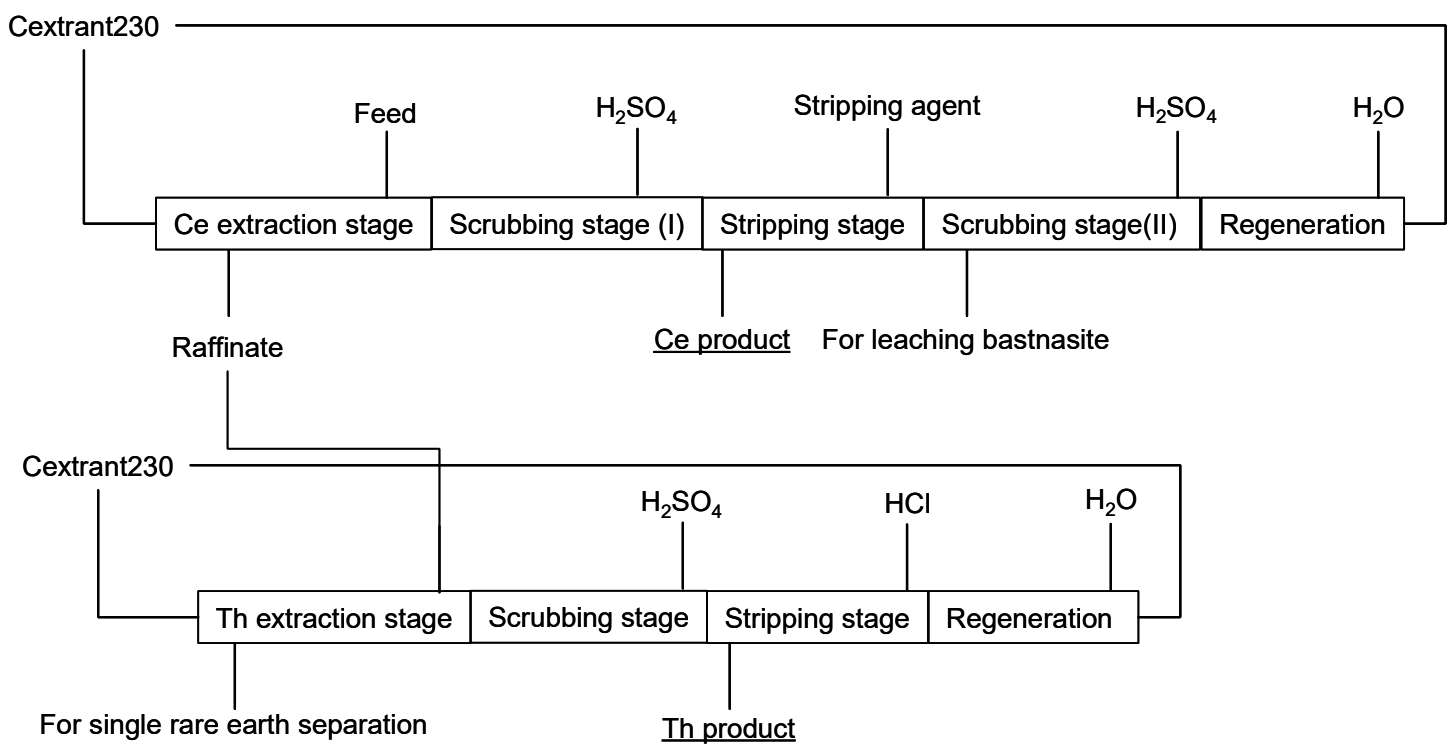

Figure 8: Flow chart of separating cerium(IV) and thorium(IV) from bastnaesite leaching (74). 


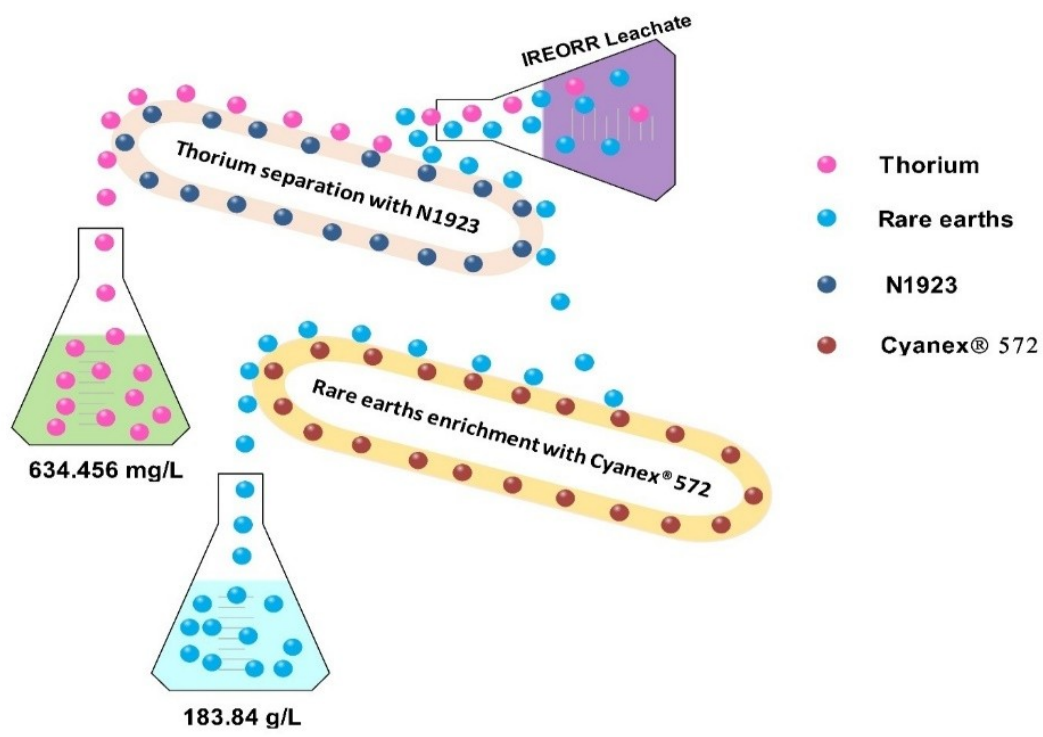

Figure 9: Th separation with N1923 and REE enrichment with Cyanex ${ }^{\circledR} 572$ (75).

Th separation with $\mathrm{N} 1923$ and REE enrichment with Cyanex ${ }^{\circledR} 572$ is shown in Figure 9. N1923 and Cyanex ${ }^{\circledR} 572$ can be used for the recovery of thorium using $\mathrm{HCl}$ leachate (75). In the method of formulating a high concentration rare earth (RE) feed for individual RE separation, hydrochloric acid is used to dissolve the RE concentrate to reduce the leaching of impurities, about $5 \%$ of REEs remains in the dissolved residues $(76,77)$.

\section{Recovery of Th from Industrial Residues and Monazite Leach Solution}

The main chemical used for this process was sulfuric acid digestion followed by water leaching. The lanthanides group as well as the scandium and yttrium group come under a rare-earth group, as the chemical structure of Th and $U$ are similar to REE. They are found in the residues generated in REE processing. In monazite minerals, Th is found in high quantity as compared to $U(78,79)$. Here the acid digestion is performed with concentrated sulfuric acid and then adds directly to the solid. Sulfuric acid digestion followed by water leaching was found to be the best method to solubilize the metal (80). To recover thorium from monazite, solvent extraction, i.e. liquid-liquid extraction process $(80,81)$. It is one of the strategic methods and utmost reliable technique to reach out on target metal recovery with enrichment factor. Korean monazite is managed using hydrometallurgical techniques such as water leaching, sulfation, double salt precipitation by using $\mathrm{Na}_{2} \mathrm{SO}_{4}$ and acidic leaching by $\mathrm{HCl}(81,82)$.
The flowchart for synthesis of thorium-rich residue associated with minor quantities of rare earth elements is shown in Figure 10.

\section{Recovery of Th from Radioactive Waste}

There is also removal of thorium using IREPO from radioactive waste (83). In this method, the recovery of Th by using IREOPR was analyzed. In this process, the convenient and effective chemical treatment of IREORR was to dissolve them with a mineral acid before recovering the valuable elements. A process for separating Th and REEs from IREORR leachate using POAA has been designed and illustrated. Here the chemical composition of residues was first analyzed and then the leaching factors such as acid type and acid concentration were noted down. A costeffective process for recovering thorium and rare earths from radioactive residues is shown in Figure 11 .

\section{EXTRACTION AND SEPARATION RESULT WITH THE OPTIMAL CONDITIONAL ANALYSIS}

The extraction process follows different steps with response to various diluents, concentration of extractants, $\mathrm{pH}$ value, temperature, contact time, acids $\left(\mathrm{HNO}_{3}, \mathrm{HCl}, \mathrm{H}_{2} \mathrm{SO}_{4}\right)$ etc. In this study, we have higlighted some important works of different researchers on exraction and separation of thorium from other metals. The parameters studied in the above said processes are calculated by using the following relations $(65,73,83)$. 


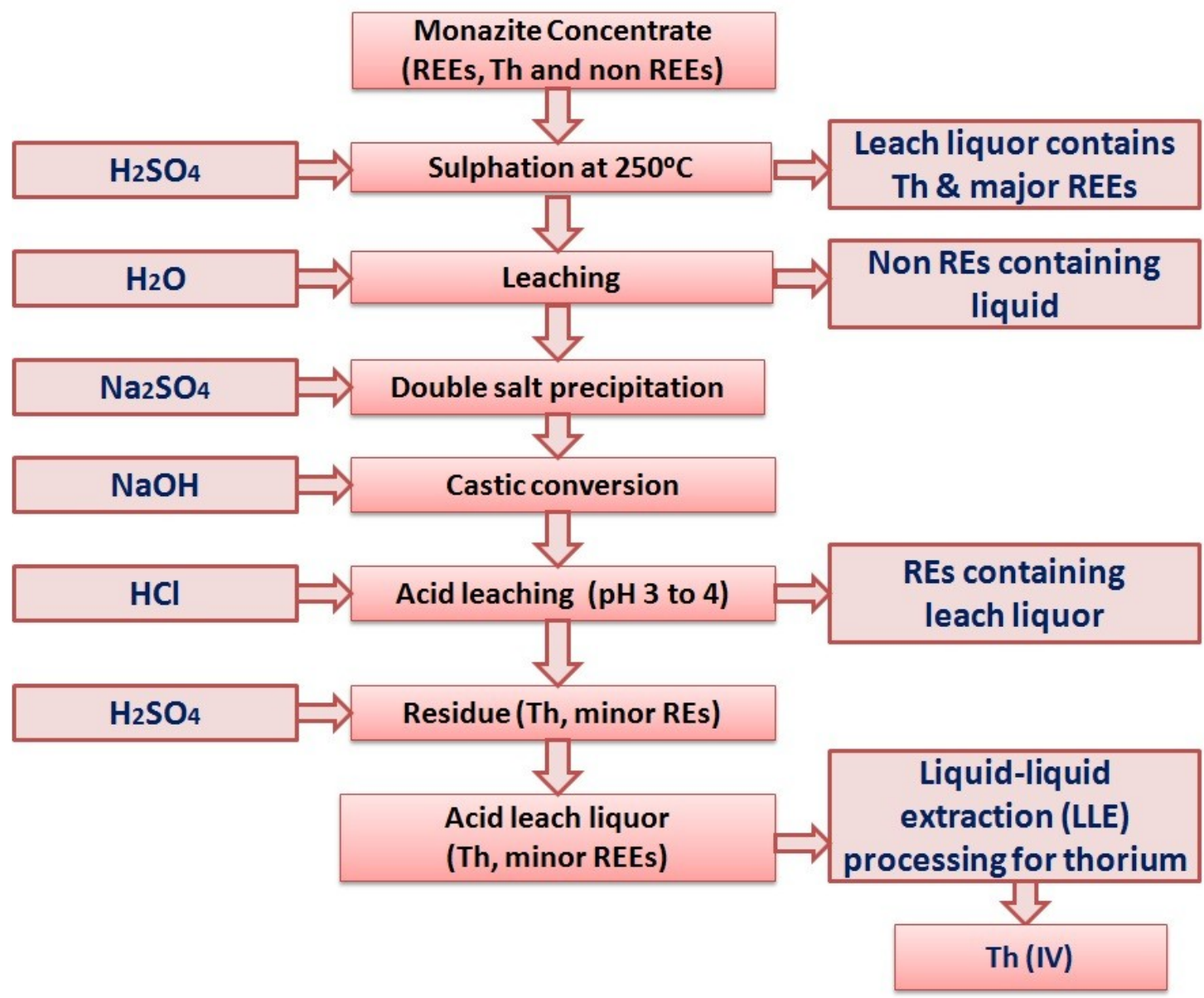

Figure 10: Flowchart for the synthesis of thorium-rich residue associated with minor quantities of rare earth elements (REE) (36).
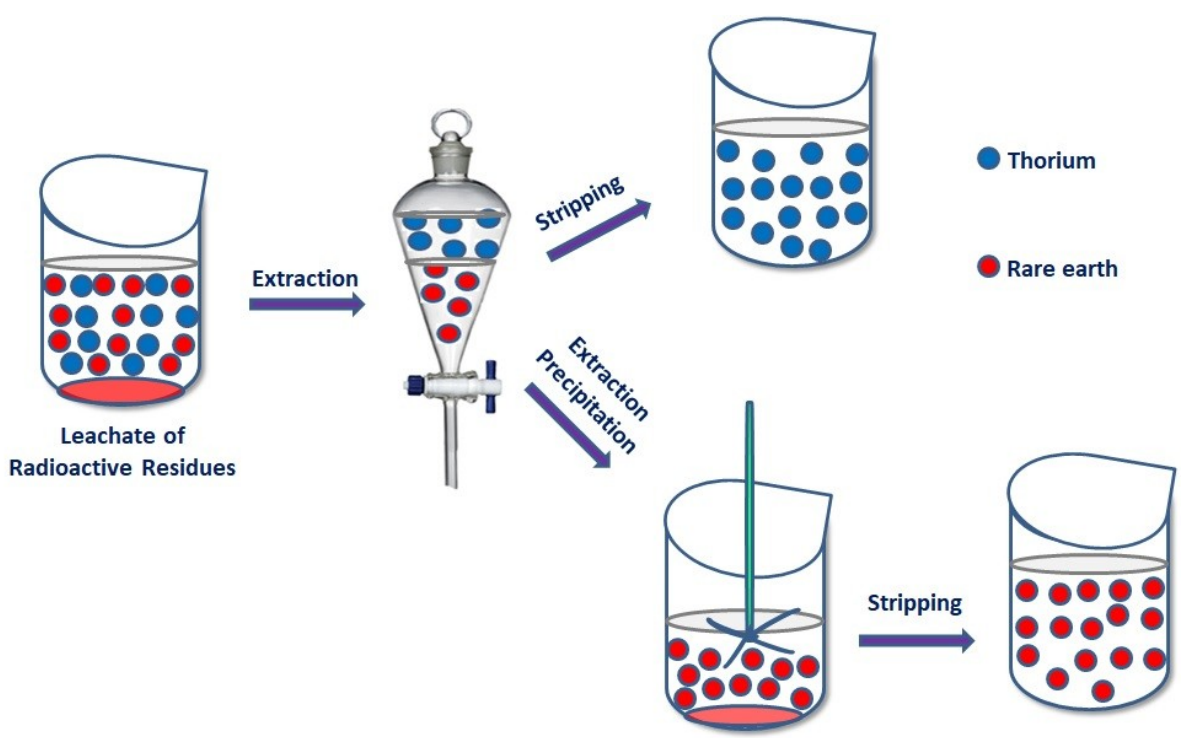

Figure 11: A cost-effective process for recovering thorium and rare earths from radioactive residues.

Distribution ratio $(D)=\frac{(M)_{O}}{(M)_{a}}$

Separation Factor $(\beta)=\frac{D_{1}}{D_{2}}$
(2) Stripping percentage (St\%) $=\frac{(M)_{a}}{(M)_{O, i}} \times 100$

(3) Extraction percentage $(\mathrm{E} \%)=\frac{(M)_{O}}{(M)_{a, i}} \times 100$ 
Where $(M)_{\mathrm{a}}$ and $(M)_{\circ}$ represent the metal concentrations in the aqueous and organic phases at equilibrium, respectively. $(M)_{a}$, i and $(M)_{0}$, i denotes the initial metal ions concentration in the aquous phase and loaded organic phase respectively.

$$
\begin{aligned}
& \text { Extractionefficiency }=\frac{C_{M(O)}}{C_{M(O)} \times C_{M(a)}} \times 100 \% \\
& \text { Recoveryefficiency }=\frac{C_{M(a)} \times V_{(a)}}{C_{M(a), i} \times V_{(a), i}} \times 100 \% \\
& \text { Stripping efficiency }=\frac{C_{M(a)} \times V_{(a)}}{C_{M(O), i} \times V_{(O)}} \times 100 \%
\end{aligned}
$$

Where $C_{M(O)}, C_{M(a)}$ are the concentration metal ions in the organic and aqueous phases respectively; $V_{(O)}$ and $V_{(a)}$ are the volume of organic and aqueous phases, respectively; $V_{(a)} i$ is the initial volume of aqueous phase; $C_{M(0)}$, i and $C_{M(a), ~ i}$ are the initial concentration of a metal in organic phase and aqueous phases, respectively.

Y. Lu et al.(74) reported the separation factors between $\mathrm{Ce}(\mathrm{IV})$ and $\mathrm{Th}(\mathrm{IV})$ at different acidity concentration and their work has shown a recovery of thorium $98 \%$ by using a -aminophosphate in acid concentration of $\mathrm{H}_{2} \mathrm{SO}_{4} . \mathrm{X}$. Yang et al. (73) found the separation factors between Th(IV) and other metal ions (RE, Fe and Al) at different acidity concentrations. The values of separation factor are higher than 160 at $1.0 \mathrm{~mol} / \mathrm{L}$ of $\mathrm{H}^{+}$ion. So, Cextrant 230 can be used as a good extractant for the removal of thorium from a mixed solution of REs and other metals (Fe, $\mathrm{Al}$ etc.). The extraction capacity of $5 \%(\mathrm{v} / \mathrm{v})$ cextrant 230 for Th(IV) was found $4.08 \mathrm{~g} / \mathrm{L}$. Again, J. Su et al. (74) reported a fractional extraction experiment for separating thorium and enriching of rare earth elements. They found the yield of Th is higher than $99.9 \%$ and the concentration of rare earth elements was 183.89 $\mathrm{g} / \mathrm{L}$. Chung et al. (36) reported that $2.5 \mathrm{~mol} / \mathrm{L}$ acidic conditions was suitable for their work. $\mathrm{HCl}$ and $\mathrm{H}_{2} \mathrm{SO}_{4}$ were tested for recovery of the thorium and $\mathrm{HCl}$ showed better results than $\mathrm{H}_{2} \mathrm{SO}_{4}$. Higher molar $\mathrm{HCl}\left(5 \mathrm{~mol} / \mathrm{L}, 250^{\circ} \mathrm{C}\right.$ ) appears to be suitable for thorium. As reported by $S M$ Ghag and $S$ D Pawar (84), the separation of Th(IV) and U(VI) from multicomponent mixtures with cyanex ${ }^{\circledR}-923$ in toluene with specific concentrations with acid, Th(IV) was found to be $99.3 \%$ in a $20 \mu \mathrm{g}$ sample. $\mathrm{U}$ (VI) and Th(IV) were extracted in the acid concentration range $5 \times 10^{-5}$ to $1 \times 10^{-4} \mathrm{M}$ and $5 \times$ $10^{-5}$ to $5 \times 10^{-3} \mathrm{M}$ respectively.. J C Amaral et al. (78) proposed a process to recover Thorium, Uranium and REs from an industrial residue. Under the optimized condition, the metal dissolution of $81 \%$ (using $\mathrm{H}_{2} \mathrm{SO}_{4}$ ) for thorium was obtained. $\mathrm{S} M$
Ibrahim et al. (85), HDEHDGA provides useful selectivity for Th(IV) over light Ln(III) ions, giving new processes for actinides-lanthanides extraction/separation and REs production in the industry. . Sulfuric acid digestion followed by water action was found to be the simplest technique to solubilize the metals.

\section{CONCLUSIONS}

The different methods of extraction of thorium such as selective extraction of thorium using phosphorodiamidate, selective cloud point extraction of thorium, extraction of thorium from sulfuric acid baking and leaching of monazite, extraction of thorium from chloride solution using Schiff base were discussed. Out of all the discussed methods of extraction, cloud point extraction is considered the best of all as it is more precise, accurate, and cheap as compared with other methods. The method is environmentally friendly as it gives very few toxic by-products. $\mathrm{HCl}$ and $\mathrm{H}_{2} \mathrm{SO}_{4}$ were taken for recovery of the metallic element and the former one is showing better results over latter one. Later on, high molar $\mathrm{HCl}(5$ $\mathrm{mol} / \mathrm{L}$ ) seems to be appropriate for metallic element recovery. The primary aims of all these methods of extractions and recoveries of thorium are for getting an efficient amount of thorium and procedure to get high efficiency of thorium.

\section{CONFLICT OF INTEREST}

The authors declared no conflict of interest.

\section{ACKNOWLEDGMENTS}

The authors are thankful to Prof. Bipin B. Swain, former Professor of Khallikote University, Berhampur, India; Prof. Sarat Kumar Dash, Department of Physics, Regional Institute of Education, Bhubaneswar, India; Dr. Wael I. Mortada, Clinical Chemistry Laboratory, Urology and Nephrology Center, Mansoura University, Egypt; Dr. Zeinab Farouk Hassan AKL, Nuclear Safeguards and Physical Protection Department, Egyptian Atomic Energy Authority (EAEA), Egypt; Dr. Liao Wuping, State Key Laboratory of Rare Earth Resource Utilization, Changchun Institute of Applied Chemistry, Chinese Academy of Sciences, Changchun, China and Dr. Mohammed Farid Cheira, Research Sector, Nuclear Materials Authority, Cairo, Egypt for their valuable inputs in preparing our review article.

\section{REFERENCES}

1. Aziman ES, Ismail AF, Muttalib NA, Hanifah MS. Investigation of thorium separation from rareearth extraction residue via electrosorption with carbon based electrode toward reducing waste volume. Nuclear Engineering and Technology. 2021 Sep;53(9):2926-36. <DOI . 
2. Kademani B, Vijai K, Anil S, Anil K, Lalit M, Surwase G. Scientometric dimensions of thorium research in India. DESIDOC Bull Inf Technol. 2006;26(3):9-25.

3. Balakrishna $\mathrm{P}$. $\mathrm{ThO}_{2}$ and $(\mathrm{U}, \mathrm{Th}) \mathrm{O}_{2}$ processing $-\mathrm{A}$ review. NS. 2012;04(11):943-9. <DOI>.

4. Humphrey UE, Khandaker MU. Viability of thorium-based nuclear fuel cycle for the next generation nuclear reactor: Issues and prospects. Renewable and Sustainable Energy Reviews. 2018 Dec;97:259-75. <DOI>.

5. Badash L. The discovery of thorium's radioactivity. J Chem Educ. 1966 Apr;43(4):219. $\leq$ DOI $>$.

6. Ünak T. What is the potential use of thorium in the future energy production technology? Progress in Nuclear Energy. 2000 Jan;37(1-4):137-44. $\leq \mathrm{DOI}>$.

7. Wilson D. The use of thorium as an alternative nuclear fuel [Internet]. Australian Atomic Energy Commission; 1982 [cited 2021 Nov 1]. $\leq$ URL $>$.

8. Lu $Y$, Wei $H$, Zhang $Z$, Li $Y$, Wu G, Liao W. Selective extraction and separation of thorium from rare earths by a phosphorodiamidate extractant. Hydrometallurgy. 2016 Aug;163:1927. $\leq$ DOI $>$.

9. Tani $H$, Kamidate $T$, Watanabe H. Micellemediated extraction. Journal of Chromatography $A$. 1997 Sep;780(1-2):229-41. <DOI>.

10. Gupta CK, Krishnamurthy N. Extractive metallurgy of rare earths. International Materials Reviews. 1992 Jan;37(1):197-248. <DOI>.

11. Cheira MF, Orabi AS, Hassanin MA, Hassan SM. Solvent extraction of thorium (IV) from chloride solution using Schiff base and its application for spectrophotometric determination. Chemical Data Collections. 2018 Mar;13-14:84-103. <DOI>.

12. Eskandari Nasab M. Solvent extraction separation of uranium(VI) and thorium(IV) with neutral organophosphorus and amine ligands. Fuel. 2014 Jan;116:595-600. <DOI>.

13. Tan M, Huang C, Ding S, Li F, Li Q, Zhang L, et al. Highly efficient extraction separation of uranium(VI) and thorium(IV) from nitric acid solution with di(1-methyl-heptyl) methyl phosphonate. Separation and Purification Technology. 2015 May;146:192-8. <DOI>.

14. Dong $Y$, Li S, Su $X$, Wang $Y$, Shen $Y$, Sun $X$. Separation of thorium from rare earths with high- performance diphenyl phosphate extractant. Hydrometallurgy. 2017 Aug;171:387-93. <DOI>.

15. Kalina DG, Mason GW, Philip Horwitz E. The thermodynamics of extraction of $U(V I)$ and Th(IV) from nitric acid by neutral phosphorus-based organic compounds. Journal of Inorganic and Nuclear Chemistry. 1981 Jan;43(1):159-63. $\leq$ DOI $>$.

16. Lu $Y, B i Y$, Bai $Y$, Liao W. Extraction and separation of thorium and rare earths from nitrate medium with $p$-phosphorylated calixarene: Extraction and separation of thorium and rare earths with calixarene derivative. J Chem Technol Biotechnol. 2013 Oct;88(10):1836-40. <DOI>.

17. Sun $X$, Dong $Y$, Wang $Y$, Chai $Y$. The synergistic extraction of heavy rare earth elements using EHEHP-type and BTMPP-type functional ionic liquids. RSC Adv. 2015;5(61):49500-7. <DOI>.

18. Prabhu DR, Sengupta A, Murali MS, Pathak PN. Role of diluents in the comparative extraction of Th(IV), U(VI) and other relevant metal ions by DHOA and TBP from nitric acid media and simulated wastes: Reprocessing of U-Th based fuel in perspective. Hydrometallurgy. 2015 Dec; 158:132-8. <DOI $>$.

19. Bezerra MA, Ferreira da Mata Cerqueira UM, Ferreira SLC, Novaes CG, Novais FC, Valasques GS, et al. Recent developments in the application of cloud point extraction as procedure for speciation of trace elements. Applied Spectroscopy Reviews. 2021 May 12;1-15. <DOI $>$.

20. Bezerra M de A, Arruda MAZ, Ferreira SLC. Cloud Point Extraction as a Procedure of Separation and Pre-Concentration for Metal Determination Using Spectroanalytical Techniques: A Review. Applied Spectroscopy Reviews. 2005 Nov;40(4):269-99. <DOI>.

21. Liu J, Liu R, Yin Y, Jiang G. Triton X-114 based cloud point extraction: a thermoreversible approach for separation/concentration and dispersion of nanomaterials in the aqueous phase. Chem Commun. 2009;(12):1514. <DOI>.

22. Mortada WI. Recent developments and applications of cloud point extraction: A critical review. Microchemical Journal. 2020 Sep1; 157:105055. <DOI >

23. Khalifa ME, Kenawy IMM, Hassanien MM, Elnagar MM. Mixed Micelle-mediated Extraction and Separation of Scandium from Yttrium and Some Lanthanide Ions. Anal Sci. 2016;32(4):395-400. $\leq \mathrm{DOI}>$.

24. Stalikas CD. Micelle-mediated extraction as a tool for separation and preconcentration in metal 
analysis. TrAC Trends in Analytical Chemistry. 2002 May;21(5):343-55. <DOI>.

25. Ravi Kumar K, Shyamala P. Catanionic mixed micellar cloud point extraction of metal ions in coal fly ash samples and their determination by CSETAAS. Journal of Environmental Chemical Engineering. 2019 Jun;7(3):103119. <DOI> .

26. Akl ZF, Hegazy MA. Selective cloud point extraction of thorium (IV) using tetraazonium based ionic liquid. Journal of Environmental Chemical Engineering. 2020 Oct;8(5):104185. $\leq \mathrm{DOI}>$.

27. Demol J, Ho E, Senanayake G. Sulfuric acid baking and leaching of rare earth elements, thorium and phosphate from a monazite concentrate: Effect of bake temperature from 200 to $800{ }^{\circ} \mathrm{C}$. Hydrometallurgy. 2018 Aug;179:25467. $\leq \mathrm{DOI}>$.

28. Xie F, Zhang TA, Dreisinger D, Doyle F. A critical review on solvent extraction of rare earths from aqueous solutions. Minerals Engineering. 2014 Feb;56:10-28. <DOI>.

29. Zhu Z, Pranolo Y, Cheng CY. Separation of uranium and thorium from rare earths for rare earth production - A review. Minerals Engineering. 2015 Jun;77:185-96. <DOI.

30. Zhang Z, Jia Q, Liao W. Progress in the Separation Processes for Rare Earth Resources. In: Handbook on the Physics and Chemistry of Rare Earths [Internet]. Elsevier; 2015 [cited 2021 Nov 1]. p. 287-376. $\leq U R L>$.

31. Teixeira LAV, Silva RG, Majuste D, Ciminelli V. Selective Extraction of Rare Earth Elements from Complex Monazite Ores. In: Davis BR, Moats MS, Wang S, Gregurek D, Kapusta J, Battle TP, et al., editors. Extraction 2018 [Internet]. Cham: Springer International Publishing; 2018. p. 238190. (The Minerals, Metals \& Materials Series). Available from: $\leq$ URL $>$.

32. Moustafa MI, Abdelfattah NA. Physical and Chemical Beneficiation of the Egyptian Beach Monazite: Beneficiation of monazite. Resource Geology. 2010 Aug 24;60(3):288-99. <DOI>.

33. Lim H, Ibana D, Eksteen J. Leaching of rare earths from fine-grained zirconosilicate ore. Journal of Rare Earths. 2016 Sep;34(9):908-16.

34. Berry L, Agarwal V, Galvin J, Safarzadeh MS. Decomposition of monazite concentrate in sulphuric acid. Canadian Metallurgical Quarterly. 2018 Oct 2;57(4):422-33. <DOI>.

35. Kumari A, Jha MK, Yoo K, Panda R, Lee JY, Kumar JR, et al. Advanced process to dephosphorize monazite for effective leaching of rare earth metals (REMs). Hydrometallurgy. 2019 Aug;187:203-11. <DOI>.

36. Chung KW, Yoon H-S, Kim C-J, Lee J-Y, Jyothi RK. Solvent extraction, separation and recovery of thorium from Korean monazite leach liquors for nuclear industry applications. Journal of Industrial and Engineering Chemistry. 2020 Mar;83:72-80. $\leq \mathrm{DOI}$.

37. Demol J, Ho E, Soldenhoff K, Senanayake G. The sulfuric acid bake and leach route for processing of rare earth ores and concentrates: A review. Hydrometallurgy. 2019 Sep;188:123-39. $\leq \mathrm{DOI}>$.

38. Mccoy $\mathrm{H}$. Method of manufacturing thorium nitrate. US 1,366,128.

39. Pilkington ES, Wylie AW. Production of rare earth and thorium compounds from monazite. Part I. J Chem Technol Biotechnol. 1947 Nov;66(11):387-94. <DOI>.

40. Urie RW. Pilot plant production of rare earth hydroxides and thorium oxalate from monazite. J Chem Technol Biotechnol. 1947 Dec;66(12):4379. $\leq \mathrm{DOI}>$.

41. Shaw K. A process for separating thorium compounds from monazite sands [PhD Thesis]. Iowa State University; 1953.

42. Barghusen J, Smutz M. Processing of Monazite Sands. Ind Eng Chem. 1958 Dec;50(12):1754-5. $\leq$ DOI $>$.

43. Borrowman S, Rosenbaum J. Recovery of thorium from a Wyoming ore. US Department of the Interior, Bureau of Mines; 1962.

44. Tobia SK. Separation of the light lanthanons from Egyptian monazite. J Appl Chem. 2007 May 4;13(4):189-92. <DOI>.

45. Kawamura $\mathrm{K}$, Takeuchi $\mathrm{T}$, Ando $\mathrm{T}$. Direct recovery of thorium and rare earths as sulphate precipitates from digestion mass. Trans Nat Res Inst Met (Japan). 1966;8(1).

46. Shamsuddin M. Hydrometallurgy. In: Physical Chemistry of Metallurgical Processes, Second Edition [Internet]. Cham: Springer International Publishing; 2021. p. 429-529. (The Minerals, Metals \& Materials Series). $\leq \mathrm{URL}>$.

47. Teriele W. A process for the recovery of mixed rare-earth oxides from monazite. National Inst. for Metallurgy; 1982.

48. Al-Fulaij O, Abdel-Aziz I. Extraction of lanthanons from Egyptian monazite. Ind J Chem. 1996;35(2):168-9. $\leq U R L>$. 
49. Chen $Y$, Wei $Y$, He L, Tang F. Separation of thorium and uranium in nitric acid solution using silica based anion exchange resin. Journal of Chromatography A. 2016 Sep;1466:37-41. $<$ DOI $>$.

50. Papangelakis V, Moldoveanu G. Recovery of rare earth elements from clay minerals. In Milos; 2014. p. 191-202.

51. Ahmed S, Helaly O, Abd El-Ghany $M$. Evaluation of rare earth double sulphate precipitation from monazite leach solutions. INt ] Inorg Bioinorg Chem. 2015;5(1):1-8.

52. Singh $H$, Gupta CK. Solvent Extraction in Production and Processing of Uranium and Thorium. Mineral Processing and Extractive Metallurgy Review. 2000 Sep;21(1-5):307-49. $\leq \mathrm{DOI}$.

53. Bunzli J, Pecharsky V. Handbook on the Physics and Chemistry of Rare Earths: Including Actinides. Elsevier; 2016.

54. Sadri F, Rashchi F, Amini A. Hydrometallurgical digestion and leaching of Iranian monazite concentrate containing rare earth elements $\mathrm{Th}, \mathrm{Ce}$, $\mathrm{La}$ and $\mathrm{Nd}$. International Journal of Mineral Processing. 2017 Feb;159:7-15. <DOI>.

55. Soltani F, Abdollahy M, Petersen J, Ram R, Becker $M$, Javad Koleini SM, et al. Leaching and recovery of phosphate and rare earth elements from an iron-rich fluorapatite concentrate: Part I: Direct baking of the concentrate. Hydrometallurgy. 2018 May; 177:66-78. <DOI>.

56. da Silva RG, de Morais CA, Teixeira LV, de Oliveira ÉD. Selective removal of impurities from rare earth sulphuric liquor using different reagents. Minerals Engineering. 2018 Oct;127:238-46. $\leq \mathrm{DOI}>$.

57. Patkar S, Burungale A, Patil R. Separation and liquid-liquid extraction of thorium (IV) as sulphate complex with synergistic mixture of Nn-octylaniline and trioctylamine as an extractant. Rasayan J Chem. 2009;2:4825-32.

58. Sehati N, Shiri-Yekta Z, Zamani AA, Yaftian MR, Noshiranzadeh N. Solvent Extraction of Th(IV) and Eu(III) Ions by 3,5-di- tert -butyl-2-HydroxyBenzaldehyde Oxime from Aqueous Chloride Media. Separation Science and Technology. 2012 Mar;47(5):670-6. <DOI .

59. Curtui M, Haiduc I, Haiduc I. Solvent extraction of thorium (IV) with dialkyldithiophosphoric acids. Journal of Radioanalytical and Nuclear Chemistry Letters. 1992 May;165(2):95-105. <DOI>.
60. Bayyari MA, Nazal MK, Khalili FI. The effect of ionic strength on the extraction of thorium(IV) from perchlorate solution by didodecylphosphoric acid (HDDPA). Arabian Journal of Chemistry. 2010 Apr;3(2):115-9. <DOI $>$.

61. Panda CR, Chakravortty V, Dash KC. A quadridentate Schiff base as an extractant for thorium/IV/, uranium/VI/ and zirconium/IV/. Journal of Radioanalytical and Nuclear Chemistry Letters. 1987 Jan;108(2):65-75. <DOI>.

62. Pawar RR, Suryavanshi VJ, Salunkhe ST, Patil SS, Mulik GN. Liquid-liquid extraction of thorium(IV) with N-n-heptylaniline from acid media. J Radioanal Nucl Chem. 2017 Jan;311(1):419-26. <DOI>.

63. Binnemans $K$, Jones PT, Blanpain $B$, Van Gerven T, Pontikes Y. Towards zero-waste valorisation of rare-earth-containing industrial process residues: a critical review. Journal of Cleaner Production. 2015 Jul;99:17-38. <DOI>.

64. Sinha S, Abhilash, Meshram P, Pandey BD. Metallurgical processes for the recovery and recycling of lanthanum from various resources-A review. Hydrometallurgy. 2016 Mar;160:47-59. $\leq \mathrm{DOI}$.

65. Su J, Xu R, Ni S, Li F, Sun X. A cost-effective process for recovering thorium and rare earths from radioactive residues. Journal of Cleaner Production. 2020 May;254:119931. <DOI>.

66. Lapidus GT, Doyle FM. Selective thorium and uranium extraction from monazite: I. Single-stage oxalate leaching. Hydrometallurgy. 2015 Apr;154:102-10. <DOI>.

67. Matveeva E, Sharova E, Turanov A, Karandashev V, Odinets I. Extraction properties of $\beta$-aminophosphine oxides towards lanthanides and alkaline earth metals. Open Chemistry. 2012 Dec $1 ; 10(6): 1933-41$. <DOI>.

68. Garifzyanov AR, Zakharov SV, Kryukov SV, Galkin VI, Cherkasov RA. Liquid Extraction of Noble Metal Ions with an a-Amino Phosphonate. Russ J Gen Chem. 2005 Aug;75(8):1208-11. <DOI>.

69. Cherkasov RA, Garifzyanov AR, Bazanova EB, Davletshin RR, Leont'eva SV. Liquid extraction of some rare earth elements with aminomethylphosphine oxides. Russ J Gen Chem. 2012 Jan;82(1):33-42. <DOI>.

70. Jagodić V, Herak MJ, Šipalo B, Radošević J. Solvent extraction study of lanthanum and europium by acidic esters of aminophosphonic acids. Journal of Inorganic and Nuclear Chemistry. 1971 Aug;33(8):2651-9. <DOI>. 
71. Hung NT, Thuan LB, Thanh TC, Watanabe M, Khoai DV, Thuy NT, et al. Separation of thorium and uranium from xenotime leach solutions by solvent extraction using primary and tertiary amines. Hydrometallurgy. 2020 Dec; 198:105506. $<$ DOI $>$.

72. Chen S, Zhang Z, Kuang S, Li Y, Huang X, Liao $W$. Separation of zirconium from hafnium in sulfate medium using solvent extraction with a new reagent BEAP. Hydrometallurgy. 2017 May; 169:607-11. <DOI>.

73. Yang X, Zhang Z, Kuang S, Wei H, Li Y, Wu G, et al. Removal of thorium and uranium from leach solutions of ion-adsorption rare earth ores by solvent extraction with Cextrant 230. Hydrometallurgy. 2020 Jun; 194:105343. <DOI>.

74. Lu Y, Zhang Z, Li Y, Liao W. Extraction and recovery of cerium(IV) and thorium(IV) from sulphate medium by an a-aminophosphonate extractant. Journal of Rare Earths. 2017 Jan;35(1):34-40. <DOI>.

75. Su J, Guo X, Gao Y, Wu S, Xu R, Sun X. Recovery of thorium and rare earths from leachate of ion-absorbed rare earth radioactive residues with N1923 and Cyanex $®$ 572. Journal of Rare Earths. 2021 Oct;39(10):1273-81. <DOI>.

76. Sun $P$, Huang $K$, Wang $X$, Song $W$, Zheng $H$, Liu $H$. Separation of $V$ from alkaline solution containing $\mathrm{Cr}$ using acidified primary amine N1923 with the addition of trisodium citrate. Separation and Purification Technology. 2017 May;179:50412. $\leq \mathrm{DOI}>$.

77. Abreu RD, Morais CA. Purification of rare earth elements from monazite sulphuric acid leach liquor and the production of high-purity ceric oxide. Minerals Engineering. 2010 May;23(6):536-40. $<$ DOI $>$.

78. Amaral JCBS, Morais CA. Thorium and uraniumextraction from rare earth elements in monazite sulfuric acid liquor through solvent extraction. Minerals Engineering. 2010 May;23(6):498-503. <DOI>.
79. Amaral JCBS, Sá MLCG, Morais CA. Recovery of uranium, thorium and rare earth from industrial residues. Hydrometallurgy. 2018 Nov;181:148-55. <DOI $>$.

80. Park KH, Kim HI, Parhi PK, Mishra D, Nam CW, Park JT, et al. Extraction of metals from Mo-Ni/AI2O3 spent catalyst using H2SO4 bakingleaching-solvent extraction technique. Journal of Industrial and Engineering Chemistry. 2012 Nov; 18(6): 2036-45. <DOI>.

81. Kiegiel $K$, Abramowska A, Biełuszka $P$, Zakrzewska-Kołtuniewicz G, Wołkowicz S. Solvent extraction of uranium from leach solutions obtained in processing of Polish low-grade ores. J Radioanal Nucl Chem. 2017 Jan;311(1):589-98. $\leq$ DOI $>$.

82. Zalupski PR, Klaehn JR, Peterman DR. Complete Recovery of Actinides from UREX-like Raffinates Using a Combination of Hard and Soft Donor Ligands. II. Soft Donor Structure Variation. Solvent Extraction and Ion Exchange. 2015 Sep 19;33(6):523-39. <DOI>.

83. Su J, Gao Y, Ni S, Xu R, Sun X. A safer and cleaner process for recovering thorium and rare earth elements from radioactive waste residue. Journal of Hazardous Materials. 2021 Mar;406: 124654. <DOI>.

84. Ghag S, Pawar S. Extraction and separation of U(VI) and Th(IV) from hydrobromic acid media using Cyanex-923 extractant. J Serb Chem Soc. 2010;75(11):1549-57. <DOI>.

85. Ibrahim SM, Zhang $Y$, Xue $Y$, Yang $S$, Ma F, Tian G. Extraction of Lanthanides(III) along with Thorium(IV) from Chloride Solutions by $N, N$-di(2Ethylhexyl)-Diglycolamic Acid. Solvent Extraction and Ion Exchange. 2020 Jun 6;38(4):417-29. $<$ DOI $>$. 
